\title{
Naturaleza y especificidad del Trabajo Social: un desafío pendiente de resolver. Reflexiones para el debate
}

\begin{abstract}
Natureza e especificidade do Serviço Social: um desafio a enfrentar. Reflexões para o debate
\end{abstract}

\author{
The nature and specificity of Social Work: a \\ challenge to be resolved. Reflections for the \\ debate
}

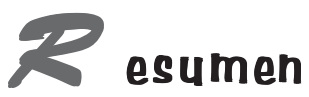

El ensayo refleja la maduración temática del autor después de sistematizar sus participaciones en diferentes eventos académicos nacionales e internacionales como ponente, expositor, conferencista y de las investigaciones realizadas sobre el tema. Su finalidad es contribuir con la discusión sobre la naturaleza y especificidad del Trabajo Social y esclarecer un viejo tema de relevancia actual como desafío pendiente. Se enfatiza que la naturaleza del Trabajo Social está constituida por el conjunto de elementos que le caracterizan y que le dan el sentido de su existencia, con una finalidad implícita o explícita, como una regularidad presente y común que tamiza el horizonte de sentido y nos identifica como Trabajadores o Asistentes Sociales, y que la especificidad no es más que un carácter distintivo dentro de la unidad de la diversidad de las ciencias sociales y que existe una naturaleza y especificidad profesionales que cimientan la identidad disciplinar.

Palabras clave: naturaleza del Trabajo Social, especificidad del Trabajo Social, estatuto profesional, legitimación, objeto de intervención.

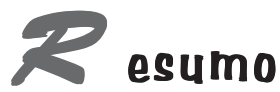

Este ensaio registra algumas reflexões do autor, que são resultado de sua participação em diversos eventos acadêmicos nacionais e internacionais nos quais apresentou pesquisas em torno do tema. A finalidade é contribuir com a discussão sobre a natureza e especificidade do Serviço Social, temática que, embora seja considerada tradicional, ainda permanece como uma pendência. Coloca-se a ênfase na consideração da natureza do Serviço Social como sendo constituída por um conjunto de elementos que imprimem sentido à sua existência e determinam certas regularidades que balizam sua trajetória e cimentam a identidade profissional. A especificidade passa aqui a ser concebida como um elemento distintivo dentro da unidade do diverso nas ciências sociais, unidade que se converte no suporte da identidade disciplinar.

Palavras-chave: natureza do Serviço Social, especificidade do Serviço Social, estatuto profissional, legitimação, objeto de intervenção.

\section{Julio César Díaz Argueta}

Coordinador Estudios de Posgrado. Escuela de Trabajo Social, Universidad San Carlos de Guatemala-USAC. 


\section{Presentación}

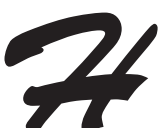

asta hace unos años, parecía que la discusión en torno a temas como el objeto, la metodología, la identidad, la ideología y la especificidad del Trabajo Social, ya no era necesaria, o al menos se había trascendido en Centro América al igual que en los demás países de América Latina. Ante el ascenso y afianzamiento del nuevo orden mundial, los cambios abruptos sucedidos en el ámbito local y global hacen reflexionar no solamente sobre los embates que sufren las ciencias sociales en general, y el materialismo histórico y dialéctico, en particular. Eso trajo consigo una serie de tendencias que llevaron a afianzar el positivismo y su variante funcionalista, y se puso en entredicho la validez de una serie de teorías y metodologías que surgieron de la reconceptualización y de la corriente materialista.

$\mathrm{Al}$ interior de la profesión, el debate sobre la naturaleza y especificidad cobra vigencia en el momento actual, y evidencia el repliegue estratégico de los seguidores de la corriente científica del materialismo histórico y dialéctico, al repensar el Trabajo Social en el marco de las ciencias sociales, compartiendo o no su anunciada crisis, pero de todos modos revitalizando la discusión de viejas temáticas con nuevos enfoques y condicionalidades. Surgen nuevos planteamientos sobre si es o no una disciplina, sin cambiar la tendencia (en la que personalmente me inscribo) de que es una disciplina en construcción y también se da la discusión sobre cuál es su ámbito de acción, la generalidad de lo social o bien lo singular de la problemática social dentro de las oleadas neoliberales y su entronización en la globalización.

Esta discusión sobre la naturaleza y especificidad del Trabajo Social sigue vigente en Guatemala y en el ámbito centroamericano, lo que motiva el presente ensayo para compartirlo con los amigos de la Revista Katálysis, con la finalidad de contribuir a motivar al sistema profesional para profundizar la reflexión sobre las distintas posturas existentes y fortalecer de esa forma la claridad pertinente sobre un viejo tema de relevancia actual, como desafío pendiente.

Con el presente ensayo se espera acotar en la discusión sobre la naturaleza y especificidad del Trabajo Social y los componentes de la profesión, cuya reflexión resurge en los últimos años, pues de cara a la globalización, se hace necesario redimensionar el futuro profesional, pensando en sus modalidades, variantes, desafíos, encrucijadas, expectativas y nuevos escenarios de aplicación ante la demanda de competitividad, movilidad y profundización de los grandes problemas sociales como la pobreza y la exclusión.

Las ideas centrales expuestas en el presente artículo indudablemente podrán ampliarse o cuestionarse por los lectores, a través de la discusión epistemológica, de la investigación y sistematización, con lo cual se obtendrá la mejor contribución de este aporte que ahora se somete a consideración.

\section{Consideraciones preliminares}

Como parte del marco contextual donde se da la discusión, es importe tener presente que en la última década: Se ha afianzado la visión positivista de las ciencias sociales con la pérdida de referentes simbólicos y el embate a las alternativas ideológicas existentes y a las mismas ciencias sociales derivado del imperio del nuevo orden mundial.

El Neoliberalismo se impone como modelo económico, deslegitimando cualquier modelo que busque la justicia social y la transformación, señalando el fin de las ideologías, pero imponiendo una nueva que conduce a la entronización del mercado.

- El capitalismo y la mundialización de los mercados constituyen la base del nuevo orden y la plena vigencia del neoliberalismo a escala global, basado en el comercio condicionado y desigual que trastoca los límites del Estado Nación.

El Estado subsidiario sustituye al Estado Interventor (de Bienestar), despojando a la población del acceso a servicios públicos eficientes, eficaces y efectivos. La democracia representativa fundamenta el sistema político privilegiado sin que genere las soluciones esperadas para toda la población y cree las condiciones de gobernabilidad adecuadas para una vida digna y plena.

- La participación pasa a reconocerse como la piedra angular de los procesos de desarrollo, pero al mismo tiempo legitima la pérdida de responsabilidades por parte del Estado.

- El discurso del desarrollo prioriza al ser humano y su carácter sostenible, trascendiendo el crecimiento económico, al menos en su enfoque discursivo.

La expectativa de la paz social aún espera alcanzarse en contextos complejos, luego de que los acuerdos formales derivados de negociaciones políticas no han sido suficientes para la pacificación de la región centroamericana.

\section{¿Existe especificidad del Trabajo Social?}

Es innegable que la existencia de enfoques o visiones generales o generalizantes presentes en la profesión del Trabajo Social han dejando huellas profundas, con la prevalencia de una formación donde cabe todo, sin aportar los resultados esperados, permeando al sistema profesional de una todología que por más cambios curriculares que han impulsado las Unidades Formadoras, no ha logrado superarse. Debo confesar sin ambages que sigo convencido de la existencia de la necesaria especificidad del Trabajo Social, a pesar de los enfoques que afirman que lo social es abordado por las ciencias sociales y que el nuevo orden 
trajo consigo la pérdida de las fronteras de las ciencias considerando que ya no es necesario preocuparse por lo específico, sino asumir la generalidad de las ciencias y aportar a ellas y nutrirse de ellas desde el abordaje de objetos de investigación e intervención concretos. La especificidad desde mi punto de vista, contribuye y facilita ese abordaje para asumir la complejidad y diversidad de objetos particulares, desde enfoques transdisciplinarios.

No es que no comparta en el fondo la flexibilización de las ciencias sociales, pero entiendo que las fronteras de la ciencia han existido en la mente del ser humano, según la corriente de pensamiento en que se inscriba, no en las ciencias mismas. La ciencia es una, con diferentes campos científicos roturados a partir de uno o varios objetos de estudio. Pero nunca han existido conocimientos propios de cada ciencia como propiedad privada, sino más bien, como ha sucedido en las mismas ciencias sociales, se han tomado de otras ciencias y se han incorporado en el abordaje de objetos específicos, atravesados por diferentes disciplinas.

De lo contrario, las ciencias sociales no definirían dichos objetos con términos, conceptos y categorías provenientes de las ciencias naturales y ciencias exactas, pues desde la consideración de la sociedad como un todo orgánico, hasta su funcionamiento como sistema y no digamos la identidad, la pertenencia, la eficiencia y la eficacia, se nutren de simbolismos de todas las ciencias. La creencia ingenua de que un conocimiento pertenece sólo a una ciencia ha sido superada. Lo importante es la perspectiva y significación en cada campo roturado de la ciencia misma, específicamente en aquellas dedicadas a describir, explicar, predecir e incidir en los fenómenos y procesos sociales en cuyo ámbito se ubica el Trabajo Social ${ }^{1}$.

Si bien cada disciplina particular desarrolla su propio lenguaje técnico y sus propias acepciones de las cosas y fenómenos que aborda, no se aleja de un lenguaje universal para todas las roturaciones científicas. El uso de términos, categorías y conceptos comunes elaborados en otros contextos científicos pasan a formar parte del metalenguaje, y con ambos: lenguaje y metalenguaje se expresan las diferentes disciplinas. En ese punto es donde se rompen las fronteras de las ciencias, pues ninguna patenta el lenguaje, sino los productos concretos, en tanto los frutos del conocimiento constituyen propiedad universal, sin que se pierda la especificad de las mismas.

Lo que no comparto es caer en los extremos totalitarios que proponen que porque las ciencias no tienen fronteras, asumamos lo mismo que le corresponde al psicólogo, un politólogo, u otro profesional, pues entonces, ¿por qué no pensar en asumir un nombre común como cientistas sociales? ¿Pero qué pasará con los objetos particulares? Más bien considero que sin especificidades no podemos llegar a las generalidades, es decir, si todos partiéramos de la misma formación, del mismo conocimiento, del mismo perfil, ¿para qué las disciplinas particulares? Sigo pensando que lo general y lo particular son momentos de un proceso dialéctico en interrelación, pero con especificidades, identidades y particularidades que pueden ser convergentes en la inter y transdisciplinariedad, pero que en ningún momento pierden su identidad ni sustituye las perspectivas disciplinares de las cuales se nutre en el abordaje de una problemática social considerada como objeto de investigación o intervención.

Claro está que al interior de cada campo roturado por una disciplina particular existe infinidad de procesos, de objetos particulares de estudio; pero eso es comprensible desde la diversidad y la complejidad del objeto marco que se aborde. En el Trabajo Social, no existe un solo objeto, sino diversidad de objetos que conforman un objeto mayor como unidad de lo diverso; a partir de ello puede hablarse de la heterogeneidad que conduce a romper el estigma de una única identidad asignada, pues históricamente se han construido identidades diversas, por lo que es válido hablar de una identidad de identidades, lo que afianza el enfoque dialéctico mismo al interior de los componentes y abordajes multidimensionales desde el ámbito disciplinar.

Comparto la idea de que existe una naturaleza y una especificidad dialécticamente concebida para el Trabajo Social, como la razón de ser y la intencionalidad, la perspectiva desde lo cual se abordan determinados campos de lo social y se interviene en ellos en forma fundamentada y sistemática desde una óptica específica.

La potencialidad de los enfoques multiprofesionales surge desde diferentes ópticas en el abordaje de múltiples objetos, su conocimiento y transformación. Sólo a manera de ejemplo, basta analizar la problemática de los niños de la calle. No existe una única visión, ni una profesión que se encargue de su abordaje exclusivo. Se pueden dar enfoques médicos para establecer su situación de salud. Pero también se requiere establecer su situación jurídica, los grupos de poder que les desatienden y los que conforman ellos mismos en microespacios locales; la situación familiar, la educación, el respeto a sus derechos humanos, su potencial humano, los problemas psicológicos afrontados; en fin, surgen diferentes aristas de un solo fenómeno; se requiere de abordajes específicos, para integrar la visión holística del mismo con el aporte multiprofesional. ¿Pero qué pasaría si todas las disciplinas abordaran el fenómeno con la misma visión generalizante, sin una perspectiva concreta desde una especificidad intrínseca?

\section{¿Hacia dónde dirigir la mirada para comprender la especificidad?}

Tal como se afirmó anteriormente, el debate sobre la temática se ha retomado en los últimos años, en diversos contextos académicos y gremiales; sin embargo con los 
cambios mundiales y su incidencia en la esfera del Estado, en la sociedad y en las políticas sociales, los elementos constitutivos del Trabajo Social deben repensarse y resignificarse, con lo cual se redimensionará también su naturaleza y su especificidad. Esa necesidad confirmará la tesis de que nada está acabado, ni autosatisfecho, sino en constante cambio por saltos cualitativos.

Es ineludible repensar entonces los elementos constitutivos del Trabajo Social, entre otros:
Su génesis;
La práctica profesional;
La conceptualización;
La metodología;
La formación profesional;
El mercado ocupacional;
La práctica profesional;

- La sostenibilidad de la profesión en el tiempo y en el espacio;

Las bases teóricas y epistemológicas;

El espacio profesional;

El objeto y sujeto del Trabajo Social;

La filosofía profesional;

- La participación social y el desarrollo humano;

- Las tendencias y perspectivas en el contexto mundial, etc.

Esa mirada crítica en sentido kantiano permitirá la contextualización y la ubicación de la legitimidad actual, las fortalezas y debilidades de la profesión, para lo cual será útil tener presentes categorías como la diversidad, heterogeneidad, complejidad, diferenciación, ambivalencia, etc., con la orientación básica de las bases epistemológicas correspondientes sin dejar de considerar que la profesión tiene una trayectoria histórica en el ámbito mundial.

\section{La naturaleza del Trabajo Social como base de la especificidad}

Como afirmo en varios de mis ensayos sobre el Trabajo Social y particularmente en mi libro Hacia la Naturaleza del Trabajo Social, publicado por el Instituto de Investigaciones de la Escuela de Trabajo Social de la Universidad de San Carlos de Guatemala, ontológicamente, en el Trabajo Social se identifica desde su origen hasta la actualidad, en una naturaleza dinámica, la misma que se ha redimensionado históricamente, pero que ha prevalecido como su razón de ser, configurando su identidad, tanto en su sentido inmanente como trascendente. En dicha naturaleza se identifica lo inmanente como lo perdurable, lo específico, lo que le es inherente, lo peculiar, lo que le caracteriza necesariamente, lo que hace que la profesión se llame Servicio Social o Trabajo Social (según el contexto) y no otra cosa; lo específico concebido en sentido dialéctico actúa como lo insustituible, lo esencial. Mientras tanto lo trascendente es lo que varía, lo que se expresa, sus alcances y límites, lo que penetra nuestros sentidos y va más allá de las formulaciones conceptuales, lo que asume modalidades diversas, estilos de aplicación, las variantes según el área de intervención, los enfoques, las técnicas empleadas, etc., de gran importancia pero que finalmente no determinan la razón de ser y la finalidad de la profesión como tal, sino su abordaje, su expresión, su inserción en la sociedad y se evidencia en la demanda institucional.

La naturaleza del Trabajo Social está constituida por el conjunto de elementos que le caracterizan y que le dan el sentido de su existencia, con una finalidad implícita o explícita, como una regularidad presente y común que tamiza el horizonte de sentido y nos identifica como trabajadores o asistentes sociales, aunque hagamos uso de conocimientos de otras disciplinas e interactuemos en los campos de otras disciplinas. La especificidad no es más que un carácter distintivo dentro de la unidad de la diversidad de las ciencias sociales. Por eso, si nos cambiamos de nombre y adoptáramos por ejemplo el de gerencia social o ingeniería social, dejaríamos de hablar de la especificidad del Trabajo Social, pero en tanto no lo hagamos, prevalece la naturaleza y especificidad profesional que cimientan la identidad disciplinar desde sus fundamentos epistemológicos.

El Trabajo Social tiene la posibilidad de aportar en un campo roturado por un contexto y un cierre categorial, una filosofía y una razón de ser, sin pretender apropiarse de ninguna intervención con exclusividad; desde una visión particular, específica, que enriquece la visión holística sobre la problemática atendida con el aporte de otras profesiones. La naturaleza y especificidad del Trabajo Social se configuran en su devenir histórico, en el ámbito de lo social, con su heterogeneidad, diversidad y complejidad, nutriendo su visión histórica-espacial, de las ciencias sociales, lo que le ha permitido cada vez más develar su papel en la legitimación del orden vigente y su funcionalidad como ejecutor de las políticas sociales. Pero el hecho de haber nacido con una identidad asignada, no significa que se asuma en sentido dogmático y determinista sin que tenga la opción de redimensionarse, porque negaría la razón dialéctica de la historia de lo social y del sujeto social formado con sentido crítico y los diferentes saltos cualitativos que construyen su devenir. Tampoco hace que se pierda la especificidad, pues tal como se ha demostrado últimamente con la onda de la modernización del Estado, se contraen las políticas sociales por el recorte del gasto social, lo cual hace que se den rupturas epistemológicas respecto a la legitimidad profesional, a su funcionalidad orgánica al Estado, a su identidad, y a todos los componentes del sistema profesional.

Si bien el Trabajo Social se institucionaliza dentro de las condiciones creadas por el desarrollo industrial y la vigencia del capitalismo, al deshumanizar el desarrollo y 
condenar a grandes masas de población a la pobreza y exclusión en medio de una lucha desigual por la subsistencia, que requiere de requiere de acciones institucionalizadas para mantener el orden vigente, en una dimensión política, social, económica y cultural, en que ya no basta la caridad y la filantropía, actualmente el Estado ya no es el principal empleador de trabajadores sociales, sino también el sector privado conformado por ONG, Organismos Internacionales, Organizaciones de Base, empresas, etc., lo cual pone en cuestión muchos estigmas que se arguyen respecto a la naturaleza e identidad asignada y su vigencia, así como su relación con otros componentes disciplinares. La tarea es ardua y presenta concretamente los desafíos de construir una identidad de identidades donde el Estado comparta con el sector privado la ocupación de los trabajadores sociales y ya no como su empleador exclusivo; es repensar la profesión para la búsqueda de una nueva legitimidad y su inserción en el contexto de las ciencias sociales y espacio profesional, así como el fortalecimiento de su naturaleza y especificidad ante los embates heredados del neoliberalismo y la globalización. Pero también conlleva el desafío de revalorizar y legitimar socialmente al Trabajo Social para dejar de ser una profesión subvaluada, con menores salarios que otros profesionales, optimizando sus aportes a la sociedad y al marco institucional de gobernabilidad democrática, desarrollo y convivencia pacífica.

La demanda profesional actual se presenta desde diferentes espacios para atender a personas en situación de pobreza y excluidas del proceso de producción y despojadas de la capacidad adquisitiva para acceder en igualdad de condiciones a un mercado cada vez más excluyente e incapaz de asignar los recursos del desarrollo con equidad e igualdad de oportunidades, limitando las condiciones de subsistencia y negando a muchas personas la posibilidad de vivir con dignidad, lo que prolonga muchas de las disfuncionalidades del sistema.

La práctica profesional surge ligada a la política social en el marco de un capitalismo que aliena la naturaleza humana y destruye los recursos naturales, negando la sostenibilidad desde sus raíces. Desde entonces el desafío es encontrar la alternativa a la identidad asignada y a la reproducción de una práctica alienada, alienante y alienadora en el medio institucional, para asumir activamente la búsqueda de la equidad y la justicia social con el propósito de acceder a una vida digna, a una vida buena y plena, éticamente concebida a la luz de las necesidades auténticamente humanas y por ende de un desarrollo humano sostenible, social, participativo, equitativo, incluyente e integral.

Si bien una de sus preocupaciones profesionales ha sido la generación de alternativas en beneficio de la población carente de bienes o servicios, a través de crear condiciones de acceso a mecanismos redistributivos, en la transición del Estado Intervencionista (o de Bienestar) al Estado Subsidiario, la especificidad del Trabajo Social se resiente. Los espacios se constriñen, pero su estructura profesional prevalece aunque redimensionada en los servicios sociales vigentes dentro de la modernización del Estado. Si bien tiende a asimilar las directrices del modelo vigente, sigue actuando con relación a carencias así como potencialidades asociadas a su labor educativa y colectiva, facilitando procesos participativos que tiendan a disminuir los problemas sociales, pero apuntando a la búsqueda del bienestar y desarrollo con justicia social. De por sí la problemática que se aborda es diversa y compleja, hasta ambivalente, sin desmedro de la naturaleza y especificidad que orientan e impregnan la acción y finalidad profesional en contextos macro o micro.

Según enfatiza Ander Egg en su amplia producción teórica, el Trabajo Social surge para ayudar al necesitado y no para transformar condiciones macro estructurales. Su especificidad puede darse en un marco conservador, reformista-desarrollista, crítico o revolucionario, de acuerdo a su inserción en la política social, y los procesos de organización, movilización y concientización que se realicen con los sectores poblacionales atendidos. Norberto Alayón (1988) plantea que el Trabajo social emerge para atenuar y aliviar los problemas de la gente y contribuir -de ese modo- a evitar la aparición de conflictos. Considera que la aspiración del Trabajo Social es contribuir con la población a posibilitar mayores niveles de bienestar social a partir de la atención de sus necesidades y problemas. Para Faleiros (1983), la práctica profesional se vuelve cada vez más compleja y no puede más ingenuamente ser reducida a entrevistas, reuniones y visitas ni a un militantismo partidario sectario; al no ser parte del proceso productivo, las acciones están desvinculadas de las relaciones sociales y de los intereses de clase que en realidad reflejan y representan, al mismo tiempo, la profesión carece de prestigio y sus profesionales aparecen como técnicos de segundo orden, con escasa preparación teórica.

Para Lima (1989), la naturaleza del Trabajo Social reflejaba su vacío epistemológico en el poco interés por esforzarse en la conceptualización de los principios, de los objetivos que orientarían su quehacer profesional, de los elementos teóricos a utilizar y, por lo tanto, de la metodología a instrumentar para hacer frente a la problemática social donde tendría que operar. Se requiere de una ruptura epistemológica con el Trabajo Social tradicional, su enfoque practicista y su finalidad de ajuste, conformismo e integración social. Si bien el Trabajo Social realiza una praxis reiterativa e ideológica, se requiere de una praxis creativa y transformadora de la realidad, siguiendo la concepción de praxis de Adolfo Sánchez Vásquez (1968).

Según Lima (1989), por la influencia del positivismo, el Trabajo Social disgregó la naturaleza social en varias esferas aisladas, y para intervenir en cada parcela ha desarrollado 
los métodos tradicionales. Con ello el enfoque del Trabajo Social asume enfoques desde lo curativo y paliativo, de donde deviene la consideración de profesión auxiliar, para-jurídica, para-social, para-médica, etc., que afortunadamente con el tiempo se ha ido redimensionando, reivindicando y dignificando con base en la autonomía y albedrío profesional.

Es común encontrar en diversos autores el consenso de que la razón de ser intrínseca es la existencia y necesidad de intervenir para atender individual o colectivamente problemas, necesidades e intereses, en forma participativa, asistencial o cogestionaria. También existe coincidencia en que el objetivo es evitar disfuncionalidades al sistema, incluyendo a todos en el beneficio del progreso social. El objeto de intervención es el ser humano con sus fenómenos concretos y cotidianos. El escenario de intervención es lo micro social. La asistencia asciende, aunque coexiste con la beneficiencia. La profesión ha expresado el papel conciliador entre las desigualdades sociales generadas por las relaciones capital-trabajo. El Trabajo Social depende de la generación de teorías de otras disciplinas sociales. Otros afirman que la preocupación de la profesión es la creación teórica de formas o procedimientos de intervención en la problemática social del individuo, grupos y comunidades, señalando la influencia marcada del positivismo y funcionalismo y que el carácter practicista de la disciplina es producto de la naturaleza impregnada de positivismo.

Se llega al planteamiento de situaciones extremas como las que hace el Centro Latinoamericano de Trabajo Social (CELATS), considerando la complejidad social del campo de intervención y la naturaleza del Trabajo Social al atribuir a la profesión indefinición, ambigüedad, burocratismo, asistencia, espontaneismo y empirismo. Además, señala la confusión entre los objetivos profesionales, los objetivos institucionales y los objetivos individuales (CELATS, 1983). Todo ello es lo que necesita redimensionarse para superar la etapa del lamento y enfrentar el viejo desafío de la naturaleza y especificidad, sin ver solamente hacia atrás, sino recuperando los aportes de la profesión y la construcción de la disciplina en su estado actual con énfasis proactivo, de estima y crítica epistemológica dinámica y pertinente, para no seguir formando profesionales que sigan pensando que no hay disciplina, que no hay teorías propias o métodos específicos, sino ubicandola en su situación real, en los avances de la construcción de la misma para dejar de inhibir el propio desarrollo profesional dentro de un nuevo relacionamiento social.

\section{Acotaciones respecto a la especificidad del Trabajo Social}

Algunos autores señalan que para que el Trabajo Social tenga especificidad, necesita de una teoría, de una metodología, de un objeto y un instrumental propios. Sin embargo, desde mi punto de vista, no pueden asumirse absolutismos, cuando sabemos que quien nutre a la profesión son las ciencias sociales y ninguna disciplina en particular reclama para sí, como tampoco lo hace el Trabajo Social, una propiedad privada de categorías o conocimientos científicos, pues lo social es tan dinámico y complejo que requiere del conocimiento producido por diferentes disciplinas y del aporte de las diferentes profesiones para atender su problemática bajo la perspectiva de su estatuto profesional, su razón de ser, su finalidad, su naturaleza y especificidad.

La especificidad se conforma por su direccionalidad, por la óptica, por la perspectiva de análisis y la concepción del mundo y del ser humano y su entorno, a partir de lo cual construye no un objeto sino múltiples objetos de intervención, en tanto las ciencias sociales constituyen un campo roturado donde se entrecruzan las diferentes disciplinas y unas a otras se nutren a través de los metalenguajes. Mientras tanto, la especificidad de toda profesión y disciplina se configura con lenguajes específicos, que sin términos exclusivos, dimensionan en determinada forma y con determinadas acepciones las formas de entender el mundo, al ser humano y su problemática y desde ahí, aportan al abordaje de la realidad social. Abundante experiencia existe al respecto, si consideramos que el Trabajo Social comparte escenarios de actuación distintos con diferentes profesiones y dirige equipos multidisciplinarios que permiten potencializar el abordaje de objetos específicos macro o micro, donde la perspectiva del Trabajo Social es vital, lo cual no sería posible, sin la especificidad misma.

La especificidad hace que cada vez se atiendam las mismas carencias y problemas sociales, sólo que en dimensiones más complejas y en condiciones y determinaciones contextuales diferentes, fundamentadas en concepciones que aunque provengan de la misma matriz epistemológica, asumen diferentes connotaciones y denotaciones científicas, culturales, políticas y sociales.

La óptica con que el Trabajo Social aborda lo social es donde encuentra su identidad, su sustentación, su funcionalidad y legitimidad, sin perder su naturaleza o su especificidad. Ésta, aunque a veces ambigua o poco interiorizada, es identificable y necesaria en el marco de la complementariedad multi y transdisciplinaria. La profesión se supone especializada en el conocimiento, análisis e interpretación de la problemática social y las formas de organización de la población en la búsqueda del bienestar y desarrollo.

Todas las profesiones sociales abordan la multidimensionalidad de los elementos de lo social, pero gracias a su especificidad sus aportes se diferencian independientemente de las interacciones que establezcan. Siempre los abordan en forma diferenciada en la 
intencionalidad y en la perspectiva específica de su intervención, además de los elementos que priorizan para intervenir en un espacio determinado.

Muchas veces se cuestiona que la especificidad requiere de la uniformidad de los trabajadores sociales, lo cual es imposible, en tanto la profesión constituye la unidad en la diversidad de formaciones, prácticas y concepciones profesionales. Sin embargo, desde el punto de vista de la intencionalidad ontológica, los seres humanos pueden tender hacia un objeto en forma dinamizada, con un propósito, lo que facilita la expansión de su conciencia social y la conformación de un actuar común, de una unidad a partir de elementos diferentes con una orientación determinada, escogiendo ciertas funciones, personas, actividades y objetivos (GUTIERREZ, 1980) lo que confirma que la especificidad no es dogmática, absoluta, sino dialéctica, relativa, esencial, compleja y se presenta como la unidad de la diversidad.

La premisa de la especificidad en Trabajo Social y en cualquier profesión lo constituye la vocación profesional, desde la cual se concibe una orientación específica dentro de un universo difuso y complejo que permite insertarse en un proyecto común en el ámbito social a través del cual se busca participar en la realización humana con fundamentos científicos, que dan sentido a la vida y a la investigación misma para el conocimiento de las diversas herramientas que facilitan la comprensión del mundo, su problemática y el alcance del bienestar y la plenitud humana. Por lo tanto, la especificidad del Trabajo Social se da en la diferenciación de intenciones, de acciones y de dimensiones del sujeto social atendidas, y no en la exclusividad o propiedad de los elementos citados. Eso es lo que hace de la profesión un ente articulado con una misión concreta, que nos diferencia, nos identifica y nos abre o restringe el espacio ocupacional.

$\mathrm{Si}$ se pierde esa especificidad compleja ¿qué tipo de interlocución tendríamos ante la realidad? ¿Con qué visión nos desempeñaríamos en un equipo multidisciplinario? ¿Cómo definiríamos al Trabajo Social? Sobre todo si sabemos que hasta el momento la profesión necesita mayor reconocimiento como profesión universitaria en diferentes latitudes y que sus aportes sean valorados en el contexto transdisciplinario.

El Trabajo Social necesita vencer una serie de estereotipos y estigmas asignados en la etapa inicial de la práctica profesional que le otorgan una visión de profesión subsidiaria a otras, pero ello no niega la especificidad, como pretende hacer el orden mundial para deslegitimar a las ciencias sociales haciendo gala de la misma postmodernidad y del proceso de cambio de paradigmas ideológicos. La especificidad de la profesión, a diferencia de muchas otras profesiones, hace que tenga un espacio y cercanía privilegiada con la población. Lejos de los seres humanos individuales o colectivos, la profesión se vuelve burocrática y no logra ser una profesión autónoma y liberal. De hecho, con los programas de redistribución del ingreso que aún existen, el capital gasta menos en el pago de los salarios, aprovechando el salario social que se brinda a través de las políticas sociales sobrevivientes, a costa del aporte de los propios ciudadanos, como sucede actualmente con las políticas neoliberales, que priorizan el poder local, el desarrollo local y la autogestión como forma de empoderar a la población pero también de desresponsabilizar al Estado de muchas de sus obligaciones.

La naturaleza y especificidad del Trabajo Social se impregna de su desempeño ligado a lo humano, en sus múltiples dimensiones. Asume una direccionalidad en su práctica al estar cerca de lo sensible, lo consciente, lo fraterno, lo espiritual, lo cotidiano, las carencias, la producción de satisfactores a las necesidades; la interrelación de individuos y grupos en el escenario social, sus condiciones y determinaciones. Por eso se vincula a los escenarios y problemas de poder, dominación, de opresión, pobreza, bienestar, injusticia y desigualdad que niegan a las grandes mayorías la plena felicidad y bienestar, que marca la calidad de vida de las personas, estableciendo su inclusión o exclusión de la distribución de la riqueza. Todo lo cual permea su discurso, su intervención y su especialización para hacer partícipes a los sujetos sociales en la búsqueda de los satisfactores básicos, para sobrevivir y alcanzar una vida digna, tarea que no es común a otras profesiones sociales, aunque atienden al ser humano en su multidimensionalidad.

Si entendemos, como señala Max-Neef (1994), a la persona humana como un ser de necesidades múltiples e interpedependientes, debemos comprender que éstas necesidades humanas conforman un sistema en que las mismas se interrelacionan e interactúan; de la misma manera las profesiones cada vez más encuentran puntos convergentes a partir de la misma diferenciación atendiendo problemas relacionados con las diferentes facetas de lo social en lo existencial: Ser, Tener, Hacer y Estar; y, por la otra en lo axiológico, las necesidades de Subsistencia, Protección, Afecto, Entendimiento, Participación, Ocio, Creación, Identidad y Libertad.

Desde lo específico se aporta su perspectiva, su visión, su potencialidad para enfrentar las condiciones y determinaciones de la distribución de la riqueza, la producción, la distribución y el consumo que marcan las condiciones de vida de las personas, priorizando a diferencia de otras profesiones, el impulso de la organización y la participación social para construir alternativas que propicien mejores niveles de vida y el pleno despliegue de las potencialidades humanas. Si bien, todas las profesiones sociales abordan la realidad, no todas lo hacen de la misma manera ni con los mismos énfasis ni en los mismos puntos focalizados.

La especificidad del Trabajo Social fundamenta su acción, su aporte a la realidad, pero no le da un dominio 
exclusivo de su campo de acción, ni le legitima en el mercado ocupacional y contexto social. El Trabajo Social está ligado a la vida cotidiana de la población como escenario privilegiado de actuación. La cotidianización de la especificidad de la profesión hace que no se valore a sí misma, por estar ligada a la resolución de problemas, satisfacción de necesidades o responder a intereses de la población, lo que aparentemente no requiere tener mayor ciencia, hacer ciencia o aplicar ciencia. Desde ahí la práctica profesional se fetichiza y marca el conformismo, el voluntarismo y hasta una visión inmediatista e individualista, lo que no niega la especificidad misma, sino solamente refleja las distorsiones que sufre en la práctica profesional, ante la falta de estrategias y de una mayor consolidación del estatuto profesional.

Es en la vida cotidiana donde se realiza cualquier opción institucionalizada, se manifiesta el ser humano como tal, con todas sus dimensiones biológicas, psicológicas, sociales, culturales, económicas, ideológicas, religiosas, etc., y donde se manifiesta la concepción del mundo, su forma de enfrentar la vida, la forma de adquirir los satisfactores, de posibilitar su sobrevivencia mediante su vinculación a la esfera de producción y reproducción y sus actitudes y valores al respecto. A partir de lo cotidiano las relaciones sociales constituyen un modo de vida en una sociedad particular. Ese modo de vida está regulado por el Estado que cumple fundamentalmente las funciones de garantizar la acumulación del capital, la reproducción de la fuerza de trabajo y la inserción al mercado mundial. Para configurar ese modo de vida en lo social, el Estado se relaciona con la sociedad civil por medio de las políticas sociales y de los compensadores sociales que tienen un carácter técnico y eminentemente político.

Es común el desfase entre la concepción del Trabajo Social que opera en la práctica profesional y la que se maneja en el contexto académico. De acuerdo a su naturaleza y especificidad, el Trabajo Social configura los objetos de intervención profesional con una concepción e intencionalidad determinada, donde el marco teórico, la metodología y el instrumental básico se asumen y se conforman según la concepción de la realidad y las actitudes ante las transformaciones requeridas por ésta. En ese sentido, la conceptualización del Trabajo Social como paradigma específico, fundamenta, orienta y permite desarrollar con directrices determinadas, implícitas y explícitas, todo un proceso formativo con suficiente base epistemológica y axiológica para fundamentar su visión e intervención en la porción de lo social en donde interviene. La especificidad del Trabajo Social se construye junto a las profesiones de las ciencias sociales que defienden la dignidad humana y hacen de la cotidianidad un escenario de lucha por la supervivencia, la organización y la construcción de las utopías de la esperanza y el clamor por la vida digna, con bienestar, paz y desarrollo, y que están comprometidas a dar sus mejores aportes desde la disciplina, fortalecidos por lo transdisciplinario para enfrentar los embates de la piraña neoliberal.

La funcionalidad y legitimidad del Trabajo Social no siempre es consciente al profesional en la instrumentalización de sus funciones, en un contexto donde el Estado o las Organizaciones no Gubernamentales (ONG) están incorporados a las políticas sociales y sus fines de control, hegemonía, legitimación, redistribución, acumulación, consenso social y participación. Además, la relación de dependencia hacia las fuentes empleadoras dificulta la posibilidad de romper con la subalternidad de la profesión y su subordinación de géneros, sin estigmatizar la prevalencia de las féminas en la profesión.

Esencialmente desde su especificidad, el Trabajo Social puede aportar a las ciencias sociales y a la solución de los problemas colectivos pues, con la vivencia acumulada gremialmente, pueden encontrarse los aprendizajes tenidos en todos los modelos ensayados para el desarrollo. Forma parte del proyecto de reivindicación de la dignidad humana y se da cuenta que la vida social implica relaciones mutuas que interaccionan entre el tiempo y el espacio, susceptibles de cambios en contextos determinados; cambios que se suceden en la mentalidad, actitud y comportamiento de las personas.

Sin embargo, la especificidad por sí misma no implica el reconocimiento como ciencia. A pesar de los esfuerzos por la producción teórica y su transición a disciplina, ese es un proceso por recorrer, pues afortunadamente todo cambia una vez que se auto reconozcan sus posibilidades y se supere su vulnerabilidad teórica y metodológica. La especificidad del Trabajo Social permite actuar en un escenario lleno de antagonismos que complejizan la relación sujeto-objeto dentro la naturaleza de lo social y de las necesidades y sus satisfactores que requieren de una resignificación de la teoría y la práctica del Trabajo Social en la construcción del objeto de investigación-intervención. La especificidad en la dimensión 
concebida no significa el cierre dogmático, ni la exclusividad a nada, sino una visión, una acción y una disposición a focalizar dentro de lo social lo que puede ser atendido por la profesión, como condición de la inter y transdisciplinariedad como práctica social específica.

El Trabajo social tiene una naturaleza, histórica-social, condicionada por el tiempo y el espacio que resignifican sus elementos constitutivos. Está claro que el Trabajo Social produce conocimiento y saberes que han dado lugar a premisas y conocimientos que abonan el salto cualitativo de práctica a disciplina en la construcción del auto reconocimiento, la elevación de nuestra autoestima y la sostenibilidad de nuestra profesión.

Por su especificidad el Trabajo Social no modifica ni necesidades, ni satisfactores sino los procesos a través de los cuales la población visualiza sus capacidades y asimila experiencias que le permiten participar activamente en la generación y superación de sus condiciones de vida.

La especificidad del Trabajo Social -con el fortalecimiento de su naturaleza resignificada- enfrentará el tránsito, motivado por la globalización, de la modernidad a la postmodernidad, la hibridación, la inequidad, la violencia, la pobreza, la heterogeneidad cultural, el desdibujamiento de fronteras, el pluralismo político y social y los cambios en la interacción humana, con el acelerado desarrollo de la informática y las telecomunicaciones en general, en forma crítica para no solamente dejarnos arrastrar por las oleadas de la postmodernidad y la ruptura de las fronteras científicas, conscientes de que necesitamos desarrollar la visión y lectura holística de la realidad como fundamento para la praxis profesional y el aporte a la construcción de un orden más equitativo y sostenible como horizonte teleológico, teórico y práctico del Trabajo Social latinoamericano.

La práctica profesional no está al margen de los juegos del poder, ni se exime de las responsabilidades políticas que median la producción de saberes que fundamentan su quehacer. Sin embargo su naturaleza y especificidad permiten contribuir a superar la incertidumbre y desesperanza que propicia el nuevo orden mundial con el anuncio del fin de las ideologías, el fin de la historia y el embate a las ciencias sociales. Desde ahí se ponen los saberes profesionales al servicio del desarrollo social, rescatando y fortaleciendo nuestra identidad, nuestra especificidad y nuestra naturaleza, situándonos frente a nuevos paradigmas teóricos pertinentes para aportar junto a otras disciplinas a la democracia, la paz, el bienestar y al desarrollo de la humanidad en contextos concretos.

\section{A manera de reflexión final}

La legitimidad de una profesión deviene de la permanencia y pertinencia de sus acciones y la respuesta que brinde a la sociedad. El desafío es el conocimiento de la realidad en su complejidad para identificar las áreas problemáticas donde se puede intervenir mono o interdisciplinariamente presentando alternativas de solución desde su óptica. La aprehensión no debe orientarse por la certeza de un saber propio, por una metodología propia, por un objeto propio en el sentido dogmático, sino por el interés en trascender las finalidades, los motivos, el saber necesario para actuar dentro de una metodología dinámica como concepción del mundo, en cuya conformación influyen los aportes de las ciencias sociales en general, como herramienta de la razón y elemento importante para que el todo de cada quien, forme parte del todo de un grupo y del todo de la sociedad. No constituye un todo con exclusividad, pero sí como parte del todo social, pues no hay razones absolutas, sino razones y el Trabajo Social tiene sus razones, su todo que es parte del todo de las ciencias sociales, sin ser el único, pues necesita fusionarse con las demás disciplinas en sentido dialéctico, para lo cual sostiene identidades y especificidades en cada uno de los niveles en que se constituye como saber práctico y cono finalidad, como intencionalidad, si no ¿a qué apuntaría?

La especificidad es una cualidad que diferencia a unos saberes y prácticas de otras, señalando la especialización que no lo da el manejo de elementos constitutivos absolutos sino construidos a partir del todo en partes para actuar dentro de la unidad de lo diverso, tal como en los procesos de investigación. El hecho de que se tenga que saber de otras disciplinas no significa que se pierda la especificidad, sino que la transdisciplinariedad diversifica la unidad y a su vez se especializa más las diferentes profesiones, asumiendo nuevas especificidades, siempre que estas no se tomen como absolutismos.

Tal como señaló hace algún tiempo Alayón (1988, p. 7), el Trabajo Social como cualquier otra disciplina, no constituye una categoría abstracta, que funciona independientemente de las determinaciones históricosociales, que se registran en tal o cual país en un período determinado... Las profesiones no pueden definirse desde ellas mismas, sino por la función que cumplen en un orden social determinado.

El fortalecimiento de la profesión no implica negar la historia, sino resignificar nuestra identidad independientemente del campo de acción, del nivel de intervención y del contexto en el que se ubique el profesional, a fin de reconocerse a sí mismo y resignificar el objeto de conocimiento y construcción del Trabajo Social como elementos básicos para la praxis académica y social.

La identidad profesional no está en sus aspectos constitutivos sino en la pertenencia a ellos, en sus fines y en los resultados con los cuales se logra legitimar la existencia del ser profesional, pasando por la conciencia social, la autoestima y la valoración del hacer, del saber y del pensar. No es factible una identidad genérica sin una identidad específica. La identidad genérica ¿será que 
no nos conduce directamente a aceptar subliminalmente la mundialización del mercado y sus efectos, despojándonos de nuestras potencialidades específicas para contribuir a buscar alternativas? Acaso basta sentirse ciudadano del mundo para acceder a los bienes y servicios o a la categoría de consumidor y receptor universal, ¿y los pobres? ¿y los excluidos?

La identidad plantea la esencia de un ente, de un conglomerado cómo ha sido, lo que puede ser, sus posibilidades, como afirma Serrano Lopez (1997, p. 344): "Quien desconoce o niega su pasado, porque no le gusta y quien, por desidia, renuncia a sus posibilidades se desvanece como sujeto, como identidad apropiada [...] el tener límite, el ser finito no es una carencia del ser, no es una falla del ser, sino su condición de posibilidad."

De ahí que comparta la necesariedad de sentirnos parte de las ciencias sociales, pero no de abarcarlas todas, pues la diferencia pertenece a la unidad como totalidad y es un estado pero también un proceso en el cual la profesión no puede sólo llegar a producir conocimientos para sí, sino también para lo social. Es imprescindible preocuparnos por el origen del conocimiento y el destino del conocimiento que podamos generar, pero también por nuestro reconocimiento como profesión, porque aunque en el futuro aportemos a lo social, lo haremos mejor desde el punto de vista de la especificidad para hacerlo con dominio, con relevancia y pertinencia, asumiendo la identidad de identidades y la unidad como síntesis de lo diverso.

En sí la especificidad condensa la esencia de la profesión, con lo cual configura su existencia y las formas de ser, hacer y conocer y los saberes propios que definen e identifican al Trabajo Social. Comparto la idea de que el trabajador o asistente social es un profesional que vende su fuerza de trabajo a cambio de un salario regularmente, pero no comparto el hecho de que por develar una cuestión ideológica donde el Trabajo Social se concibió en algún momento histórico como voluntarista o agente de cambio, se afirme que la naturaleza del Trabajo Social no exista o bien que no tenga especificidad.

Por eso vale la pena citar a Ander Egg (1985, p. 195) cuando dice:

Existe indudablemente, en el Trabajo Social un aspecto científico (todo el instrumental teórico que se maneja dentro de la profesión) y un aspecto tecnológico (el que hace a las cuestiones operativas), pero su finalidad le da a la profesión un contenido que lo trasciende. En otras palabras: el Trabajo Social va más allá de la ciencia y de la tecnología que integra en su 'corpus' como profesión. Por eso en sus tareas y en su relación a otras profesiones, es de quien se puede esperar el sello de lo humano.

\section{Recebido em 30.04.2006. Aprovado em 19.06.2006.}

\section{Referencias}

ALAYÓN, N. Perspectivas del Trabajo Social. 2. ed. Buenos Aires: Editorial Humanitas, 1988.

ANDER EGG, E. ¿Qué es el Trabajo Social? Buenos Aires: Editorial Humanitas, 1985.

CELATS- Centro Latinoamericano de Trabajo Social. La práctica del trabajador social. Lima, Perú: CELATS Ediciones, 1983.

FALEIROS, V. P. Trabajo Social, ideología y método. Buenos Aires: Editorial Ecro, 1983.

GUTIÉRREZ SAENS, R. Introducción al método científico. México: Editorial Esfinge S.A., 1980.

LIMA, B. Contribución a la epistemología del Trabajo Social. Buenos Aires: Editorial Humanitas, 1989.

MAX-NEEF, M. Desarrollo a escala humana. Uruguay: Editorial Nordan Comunidad, 1994.

MONTAÑO, C. La naturaleza del Servicio Social. São Paulo: Cortez, 1998.

SERRANO LÓPEZ, A. La Aventura del conocimiento. Honduras: Logos, Ediciones Banco Central de Honduras, 1995.

VÁZQUEZ, A. S. Filosofia da praxis. Tradução Luiz Fernando Cardoso. Rio de Janeiro: Civilização Brasileira, 1968.

\section{Nota}

1 Los lectores notarán que la profesión se denomina Trabajo Social, producto de una vieja discusión saldada en el medio y consensuada en el sistema profesional vigente en el ámbito regional y en el país, sustituyendo la denominación del Servicio Social como tal.

\section{Julio César Díaz Argueta}

jucedia@gmail.com

Universidad de San Carlos de Guatemala

Departamento de Estudios de Posgrado

Escuela de Trabajo Social

Edificio S1, Ciudad Universitária, Zona 12

Guatemala, C.A. 